\title{
3 Research Square

\section{A Novel Neoagarotriose-Producing Agarase from the Marine Bacterium Gilvimarinus Agarilyticus JEA5}

\section{Youngdeuk Lee}

Korea Institute of Ocean Science and Technology

\section{Eunyoung Jo}

Korea Institute of Ocean Science and Technology

\section{Yeon-Ju Lee}

Korea Institute of Ocean Science and Technology

Hansol Choi

Korea Institute of Ocean Science and Technology

\section{Tae-Yang Eom}

Korea Institute of Ocean Science and Technology

\section{Yehui Gang}

Korea Institute of Ocean Science and Technology

\section{Yoon-Hyeok Kang}

Korea Institute of Ocean Science and Technology

\section{Svini Dileepa Marasinghe}

Korea Institute of Ocean Science and Technology

Sachithra Amarin Hettiarachchi

Korea Institute of Ocean Science and Technology

\section{Do-Hyung Kang}

Korea Institute of Ocean Science and Technology

Chulhong Oh ( $D$ och0101@kiost.ac.kr)

Korea Institute of Ocean Science and Technology https://orcid.org/0000-0002-9283-3258

\section{Research}

Keywords: $\beta$-agarase, glycoside hydrolase family 16, neoagaro-oligosaccharide, neoagarotriose, Gilvimarinus agarilyticus JEA5

Posted Date: May 19th, 2020

DOI: https://doi.org/10.21203/rs.3.rs-27597/v1 
License: (c) (i) This work is licensed under a Creative Commons Attribution 4.0 International License. Read Full License 


\section{Abstract}

Background The degradation of agar by bacterial agarases has many commercial and academic applications. We recently identified a novel neoagarotriose-producing $\beta$-agarase, Gaa16B, in the marine bacterium Gilvimarinus agarilyticus JEA5. This is the first report to describe neoagarotriose production from $\beta$-agarase.

Results The Gaa16B agarase, which belongs to the glycoside hydrolase 16 (GH16) family of $\beta$-agarases, shows less than $70.9 \%$ amino acid similarity with previously characterized agarases. The coding region of Gaa16B is 1800 bp long, encoding 600 amino acids, and exhibits features typical of agarases belonging to the $\mathrm{GH} 16$ family. A recombinant Gaa16B lacking the carbohydrate binding region (rGaa16Bc) was overexpressed in Escherichia coli and purified as a maltose-binding protein (MBP) fusion protein. Activity assays revealed the optimal temperature and $\mathrm{pH}$ of rGaa $16 \mathrm{Bc}$ to be $55^{\circ} \mathrm{C}$ and $\mathrm{pH} 6-7$, respectively, and the protein was highly stable at $55^{\circ} \mathrm{C}$ for $90 \mathrm{~min}$. Additionally, rGaa16Bc activity was strongly enhanced (2.3-fold) in the presence of $2.5 \mathrm{mM} \mathrm{MnCl}_{2}$. The $K_{\mathrm{m}}$ and $V_{\max }$ of rGaa16Bc for agarose were $6.4 \mathrm{mg} / \mathrm{ml}$ and $953 \mathrm{U} / \mathrm{mg}$, respectively. Thin layer chromatography analysis revealed that $\mathrm{rGaa} 16 \mathrm{Bc}$ can hydrolyze agarose into neoagarotetraose, neoagarotriose, and neoagarobiose, and the production of neoagarotriose by rGaa16Bc was successfully validated by high-resolution electrospray ionization mass spectrometry.

Conclusion The biochemical properties of Gaa16B and the results of the hydrolytic pattern analysis suggest that Gaa16B could be useful to produce functional neoagaro-oligosaccharides for industrial applications.

\section{Background}

Agar is the main component of the cell wall in several species of red seaweed and consists of a mixture of two polysaccharides: agarose and agaropectin. Agarose consists of a linear chain of alternating 3-0linked $\beta$-D-galactopyranose and 4-0-linked 3,6-anhydro-a-L-galactose units [1]. Agar is widely used as a gelling substance in the pharmaceutical, cosmetic, and food industries, as well as in the life sciences, where it is used in a range of techniques including microbiome culturing media, electrophoresis gel, and chromatography resin. In addition to these classical applications, recent studies have reported that many agar-derived oligosaccharides exhibit various biological and therapeutic properties, and hence have the potential for diverse applications in the cosmetic, medicinal, and pharmaceutical industries $[2,3]$.

Agarases hydrolyze both agar and agarose, and based on the mechanism of their actions, they are categorized two main groups, namely a-agarases and $\beta$-agarases. The $a$-agarases hydrolyze $\mathrm{a}-1,3-$ linkages between the composite sugars in agarose to generate agaro-oligosaccharides, while $\beta$-agarases hydrolyze only $\beta$-1,4-linkages in agarose to generate neoagaro-oligosaccharides. The $\beta$-agarases are classified into four families on the basis of their amino acid sequence homology: glycoside hydrolase 16 (GH16), GH50, GH86, and GH118 [4]. To date, many $\beta$-agarases have been found from many different 
genera including Agarivorans [5], Alteromonas [6], Bacillus [7], Catenovulum [8], Pseudoalteromonas[9], Pseudomonas [10], Vibrio [11], Streptomcyes [12], Saccharophagus [13] and Gilvimarinus [14].

Of the many agarases that have been reported, most of them are $\beta$-agarases, except for some $\alpha$-agarases isolated from Alteromonas agarilyticus GJ1B [15], Thalassomonas agarivorans JAMB-A33, Catenovulum agarivorans[16] and Caternovulum sediminis WS1-A [17]. Several reports have described that $\beta$-agarases hydrolyze agarose to produce various neoagaro-oligosaccharides such as neoagarobiose, neoagarotetraose, and neoagarohexaose [1]. However, to our knowledge, an agarase that produces neoagarotriose has not yet been reported. In this study, we identified that the gene gaa $16 b$, isolated from the marine bacterium Gilvimarinus agarilyticus JEA5, encodes a novel neoagarotriose-producing $\beta$ agarase. We cloned the gaa16b gene and overexpressed it as a recombinant protein in E. coli BL21 (DE3). Maltose-binding protein (MBP)-tagged Gaa16B was then purified and analyzed to investigate its biochemical properties and hydrolytic patterns.

\section{Results}

\section{Molecular characteristics}

We have previously published a draft genome of the marine bacterium Gilvimarinus agarilyticus JEA5, which exhibits agarolytic activity [18], and identified Gaa16B as a predicted agarase. The nucleotide sequence of gaa $16 \mathrm{~b}$ has an open reading frame (ORF) of $1800 \mathrm{bp}$, encoding a putative agarase of 600 amino acid residues. The molecular mass and isoelectric point $(p l)$ of Gaa16B were predicted to be $65 \mathrm{kDa}$ and 4.2, respectively. An analysis of the amino acid sequence predicted a signal peptide in the Nterminal region, a GH16 domain in the middle of the protein, and two carbohydrate binding module 6 (CBM6) motifs in the C-terminus. The deduced amino acid sequence of Gaa16B showed the highest identity (90.7\%) and similarity (93.8\%) with Gilvimarinus polysaccharolyticus (WP_049721028.1), whereas it exhibited less than $55.9 \%$ identity and $70.9 \%$ similarity with functional characterized agarases (Table 1). 
Table 1

Pairwise alignment analysis and comparison of the deduced amino acid sequence of Gaa16B with other $\beta$-agarases.

\begin{tabular}{|llllll|}
\hline & $\begin{array}{l}\text { Identity } \\
(\%)\end{array}$ & $\begin{array}{l}\text { Similarity } \\
(\%)\end{array}$ & $\begin{array}{l}\text { Gap } \\
(\%)\end{array}$ & Accession No. & Remark \\
\hline $\begin{array}{l}\text { Gilvimarinus } \\
\text { polysaccharolyticus }\end{array}$ & 90.7 & 93.8 & 2.7 & WP_049721028.1 & Uncharacterized \\
\hline $\begin{array}{l}\text { Gilvimarinus chinensis } \\
\text { Microbulbifer thermotolerans }\end{array}$ & 75.1 & 85.8 & 5.4 & WP_067155675.1 & Uncharacterized \\
\hline $\begin{array}{l}\text { Saccharophagus degradans } \\
2-40\end{array}$ & 55.9 & 70.9 & 4.2 & ABD80437.1 & Characterized \\
\hline $\begin{array}{l}\text { Pseudomonas sp. ND137 } \\
\text { Microbulbifer elongatus }\end{array}$ & 43.5 & 55.5 & 29.0 & BAD88713.1 & Characterized \\
\hline
\end{tabular}

\section{Overexpression of recombinant agarase Gaa16B}

To characterize the Gaa16B protein, the catalytic region (the $\mathrm{GH} 16$ domain) of the gaa $16 \mathrm{~b}$ gene was amplified by PCR and cloned into the pMal-c2x expression vector. The recombinant Gaa16B catalytic domain ( $\mathrm{rGaa} 16 \mathrm{Bc}$ ) fused to an MBP tag was expressed in E. coli BL21 (DE3) and purified using the pMal fusion protein purification system. The purified rGaa16Bc protein was electrophoresed on an SDS-PAGE gel and after staining, exhibited a strong single band with an approximate molecular mass of $75 \mathrm{kDa}$, which corresponded with the predicted molecular mass (33 kDa for rGaa16Bc plus $42 \mathrm{kDa}$ for the MBP tag) (Fig. 1.).

\section{The optimum conditions for rGaa16Bc activity}

We next investigated the effect of temperature, $\mathrm{pH}$, thermostability, and metal ions on rGaa16Bc activity. The recombinant protein was exposed to temperatures ranging from $45^{\circ} \mathrm{C}$ to $70{ }^{\circ} \mathrm{C}$, as shown in Fig. $2 \mathrm{~A}$. rGaa16Bc activity gradually increased from $45^{\circ} \mathrm{C}$ to $55^{\circ} \mathrm{C}$, exhibiting its highest agarolytic activity at $55^{\circ} \mathrm{C}$. Its activity dramatically decreased at temperatures over $60^{\circ} \mathrm{C}$ and it lost almost all activity at $70^{\circ} \mathrm{C}$. The effect of $\mathrm{pH}$ on rGaa $16 \mathrm{Bc}$ activity was tested using $\mathrm{pH}$ values ranging from 4.0 to 10.0 , in three different buffers, as shown in Fig. 2B. rGaa16Bc showed over than $80 \%$ activity in the pH range $5-8$, with its highest activity observed at $\mathrm{pH} 6$. No activity was detected at $\mathrm{pH} 4$ or $\mathrm{pH} 10$. Although the maximum activity of $\mathrm{rGaa} 16 \mathrm{Bc}$ was observed at $55^{\circ}$, the protein showed low thermostability at this temperature (Fig. 2C). It showed less than $40 \%$ activity at $55^{\circ} \mathrm{C}$ after 30 min and it lost almost activity after $60 \mathrm{~min}$. However, rGaa16Bc activity was stable at $45^{\circ} \mathrm{C}$ for up to $90 \mathrm{~min}$ and maintained approximately $80 \%$ of its activity until $120 \mathrm{~min}$. The rGaa16Bc protein was also very stable at $50{ }^{\circ} \mathrm{C}$ for $60 \mathrm{~min}$ and maintained approximately $70 \%$ of its activity until $90 \mathrm{~min}$. To determine the effect of metal ions and chelators, the enzyme assay was carried out in the presence of $2.5 \mathrm{mM} \mathrm{KCl}, \mathrm{CaCl}_{2}, \mathrm{MnCl}_{2}, \mathrm{NaCl}$, $\mathrm{MgCl}_{2}, \mathrm{CuSO}_{4}, \mathrm{ZnSO}_{4}, \mathrm{FeSO}_{4}$, or EDTA (Fig. 2D). The relative activity of rGaa16Bc was inhibited by CuSO $\mathrm{C}_{4}$ 
and $\mathrm{ZnSO}_{4}$, but was enhanced in the presence of $2.5 \mathrm{mM} \mathrm{MnCl}_{2}, \mathrm{CaCl}_{2}, \mathrm{MgCl}_{2}$, and $\mathrm{FeSO}_{4}$. In particular, $\mathrm{MnCl}_{2}$ more than doubled the activity of rGaa16Bc.

The enzymatic reactions for calculating $K_{m}$ and $V_{\text {max }}$ values were performed under optimal conditions and the results showed that the $K_{m}, V_{\text {max }}$ and $K_{c a t}$ of rGaa16Bc for agarose were $6.4 \mathrm{mg} / \mathrm{mL}, 953 \mathrm{U} / \mathrm{mg}$, and $201.2 \mathrm{~s}^{-1}$, respectively.

\section{Hydrolytic pattern of rGaa16B}

To determine the hydrolysis pattern and products of rGaa16Bc on agarose, thin layer chromatography (TLC) was used to investigate the hydrolysates at different reaction time points. The TLC results (Fig. 3) show that rGaa16Bc hydrolyzes agarose, generating various neoagaro-oligosaccharides during the initial stages of the reaction. With increasing incubation times, the ratio of the larger oligosaccharides gradually decreased while neoagarotetraose increased (Fig. 3A). After an overnight incubation, neoagarotetraose was observed to be the main product, although neoagarobiose and another spot, which we hypothesized was neoagarotriose, were also observed on the TLC plate (Fig. 3B). After hydrolyzing both neoagarotetraose and neoagarohexaose with $\mathrm{rGaa} 16 \mathrm{Bc}$, the predicted neoagarotriose was observed on the TLC plate (Fig. 3C).

A high-performance liquid chromatography (HPLC) with evaporative light scattering detector (ELSD) mass spectrometry (MS) (HPLC-ELSD-MS) analysis confirmed that rGaa16Bc hydrolyzes agarose into neoagarotetraose $\left(\mathrm{m} / \mathrm{z} 629.1[\mathrm{M}-\mathrm{H}]^{-}\right)$, neoagarotriose $\left(\mathrm{m} / \mathrm{z} 469.2[\mathrm{M}+\mathrm{H}]^{+}\right)$, and neoagarobiose $(\mathrm{m} / \mathrm{z}$ $\left.347.0[\mathrm{M}+\mathrm{Na}]^{+}\right)(\mathrm{Fig} .4 \mathrm{~A})$. The presence of neoagarotriose was further confirmed using high-resolution ESI mass spectrometry, which identified a peak with the molecular formula $\mathrm{C}_{18} \mathrm{H}_{28} \mathrm{O}_{14}(\mathrm{~m} / \mathrm{z} 467.1397$ [M$\mathrm{H}^{-}$(calculated for $\mathrm{C}_{18} \mathrm{H}_{27} \mathrm{O}_{14}$ 467.1401)) (Fig. 4B).

\section{Discussion}

We have previously reported a draft genome sequence for the agar degrading bacterium G. agarilyticus JEA5 [18], and were the first to describe the molecular characteristics and biochemical properties of a $\beta$ agarase (Gaa16A) isolated from G. agarilyticus JEA5 [19]. Here, we describe Gaa16B, a novel neoagarotriose-producing $\beta$-agarase. This newly identified agarase possesses the typical functional domains characteristic of $\beta$-agarases belonging to the $\mathrm{GH} 16$ family. Almost all GH16 $\beta$-agarases contain a GH16 domain at the N-terminus and carbohydrate binding modules in the $\mathrm{C}$-terminus of the protein [20]. Gaa16B exhibits both the GH16 domain and two carbohydrate VI modules at the $\mathrm{N}$ - and $\mathrm{C}$-termini of the protein, respectively.

The Gaa16B amino acid sequence showed the highest identity and similarity with a carbohydrate binding protein from G. polysacchariticus (WP_049721028.1), which has not yet been characterized. The NCBI database contains three genomes from the Gilvimarinus genus; however, only one agarase (Gaa16A from G. agarilyticus JEA5) has been characterized thus far [19]. Compared to the amino acid sequences of 
characterized agarases, Gaa16B displayed the highest similarity to an agarase from Saccharophagus degradans 2-40 (with a sequence identity and similarity of only $55.9 \%$ and $70.9 \%$, respectively).

To determine the optimum reaction conditions for this enzyme, we investigated the effects of temperature, $\mathrm{pH}$, thermostability, and metal ions on rGaa16Bc function. It showed the highest agarolytic activity at $55^{\circ} \mathrm{C}$ and $\mathrm{pH} 6$, although it also exhibited relatively high agarolytic activity ( $80 \%$ or more) between $\mathrm{pH} 5-8$. This high activity in a relatively wide $\mathrm{pH}$ range may be an advantage for the industrial use of rGaa16Bc. Furthermore, since agar hardens at temperatures below $40{ }^{\circ} \mathrm{C}$, it is important to have high activity above $40^{\circ} \mathrm{C}$. rGaa16B showed optimum activities at these higher temperatures, as well as under neutral ionic conditions that do not require neutralization. These properties could be particularly advantageous for industrial use.

The kinetic characterization assays revealed that the $K_{m}$ value of $\mathrm{rGaa} 16 \mathrm{Bc}(6.4 \mathrm{mg} / \mathrm{mL})$ is only slightly higher than that of other reported GH16 $\beta$-agarases, which is probably due to the absence of the CBMs. To assess the agarolytic activity of Gaa16B, the gaa $16 \mathrm{~b}$ gene was amplified without the carbohydrate binding region and cloned into a pMal-c2x vector. Most of the expressed protein was insoluble when the full length recombinant Gaa16B (including the carbohydrate binding region) was cloned and expressed in E. coli, and the soluble fraction also showed very low agarolytic activity (data not shown). In contrast, the recombinant $\mathrm{rGaa} 16 \mathrm{~B}$ without the $\mathrm{CBMs}$ showed very high activity compared to full length Gaa16B. Other studies have also reported kinetic characterizations of GH16 $\beta$-agarases lacking the CBMs and reported similar findings. A recombinant agarase containing only the $\mathrm{GH} 16$ catalytic region from $M$.

thermotolerans JAMB-A94 exhibited a higher $K_{m}$ value than the full length fusion protein [21]. In addition, Wang et al. reported that a recombinant Aga0917 lacking a CBM from Pseudoalteromonas fuligina YTW15-1 showed a remarkably high $(39.6 \mathrm{mg} / \mathrm{ml}) K_{m}$ value compare to other known $\beta$-agarases [22].

The TLC results showed that agarose was rapidly fragmented by rGaa16Bc. In the early stages of the reaction, rGaa16Bc hydrolyzed the agarose to generate neoagarobiose, neoagarotetraose, neoagarohexaose, and various larger oligosaccharides. The amount of neoagarosaccharides smaller than neoagarohexaose increased in a time-dependent manner. This hydrolytic pattern suggested that rGaa16Bc functions as an endo-type $\beta$-agarase. It has been reported that endo-type agarases randomly degrade agarose and rapidly lower the viscosity of agarose solution, while exo-type agarases tend to produce single major products and gradually decrease the viscosity of agarose solutions [23].

The rGaa16Bc enzyme produced mainly neoagarotetraose and neoagarobiose. Interestingly, the predicted neoagarotriose spot was observed to lie between those of neoagarobiose and neoagarotetraose, but it was not in line with the spot of the agarotriose which was used as a standard. To verify that rGaa16Bc does indeed produce neoagarotriose, the molecular mass of the hydrolytic products was measured by LC/MS. Electrospray ionization mass spectrometry of the reaction product showed peaks at $347.0 \mathrm{~m} / \mathrm{z}$ [neoagarobiose $+\mathrm{Na}]^{+}, 469.2 \mathrm{~m} / \mathrm{z}$ [neoagarotriose $\left.+\mathrm{H}\right]^{+}$and $629.1 \mathrm{~m} / \mathrm{z}$ [neoagarotetraose $-\mathrm{H}^{-}$. The molecular weight of agarotriose $\left(\mathrm{C}_{18} \mathrm{H}_{30} \mathrm{O}_{15}\right)$ and neoagarotriose $\left(\mathrm{C}_{18} \mathrm{H}_{28} \mathrm{O}_{14}\right)$ are 486.4 and $468.4 \mathrm{~g} / \mathrm{mol}$, respectively. The sequence of agarotriose is G-A-G (G, D-galactose; A, 3-6-anhydro-a-L-galactose), whereas 
that of neoagarotetraose is A-G-A. This is the first report to describe a neoagarotriose-producing agarase. Some a-agarases have been reported to produce agarotriose, but to our knowledge, there are no previous studies that have noted an agarase producing neoagarotriose. The a-agarase AgaD from Thalassomonas sp. LD5 was shown to hydrolyze agarotetraose and generated agarotriose with a molecular weight of $486 \mathrm{~g} / \mathrm{mol}$ and the G-A-G structural arrangement [24]. In the current study, rGaa16Bc produced neoagarotriose after hydrolyzing agarose, neoagarohexaose, and neoagarotetraose. Furthermore, it generated neoagarotriose with a molecular weight of $468 \mathrm{~g} / \mathrm{mol}$ and an A-G-A structure.

\section{Conclusions}

In conclusion, a recombinant $\beta$-agarase (rGaa16B) from Gilvimarinus agarilyticus JEA5 was cloned, overexpressed, and purified, and its biochemical properties were analyzed. This is the first report of an agarase that produces neoagarotriose. Gaa16B has a $\mathrm{GH} 16$ family domain as well as a carbohydrate binding domain, both of which are typical features of GH16 $\beta$-agarases. The Gaa16B catalytic domain showed high activity at elevated temperatures and within a relatively wide $\mathrm{pH}$ range. It also has good thermostability. These characteristics suggest that Gaa16B is a good candidate for industrial applications, such as in the cosmetic, pharmaceutical, and food industries. Further research on this agarase would require the determination of its crystal structure and a three dimensional structural analysis, in order to understand the details of the catalytic mechanism by which Gaa16B produces neoagarotriose.

\section{Methods}

\section{Molecular characterization of Gaa16B}

In our previous study, we isolated the marine bacterium Gilvimarinus agarilyticus JEA5, which exhibited agarolytic activity, and we sequenced its genome using next-generation sequencing (NGS) [18]. The predicted agarase was identified by searching the draft genome sequence of $G$. agarilyticus JEA5 (NCBI accession No. WP_041522726) using the Basic Local Algorithm Search Tool (BLAST), and was then named Gaa16B and submitted to NCBI GenBank (NCBI accession No. KP716980). Signal peptide analysis was performed using the SignalP 4.1 server [25] and conserved domains were predicted by SMART [26] and ScanProsite [27]. The identities and similarities of the Gaa16B amino acid sequence were investigated using the EMBL Pairwise Sequence Alignment Tool [28].

\section{Cloning of the gaa $16 \mathrm{~b}$ agarase gene}

We isolated genomic DNA from G. agarilyticus JEA5 (KCCM43129) using an AccuPrep® Genomic DNA Extraction Kit (Bioneer, Daejeon, Korea Rep) following the manufacturer's protocol. Primer pairs were designed to amplify only the catalytic region (GH16 domain) of Gaa16B and the resulting protein fragment was designated as Gaa16Bc. Gaa16B-F (5'- TTC AGA ATT CGG ATC GCC GAC TGG GAC GGC TTA - 3') and Gaa16B-R (5'- TTG CCT GCA GGT CGA CTA GGT AAT GTC GTT ATC GCC GCC ATT GT-3') 
primers were designed so that the $5^{\prime}$ region shares $15 \mathrm{bp}$ with the both ends of the $B a m H$ and Sall digested vector sequence. The PCR mixture consisted of $1 \mu \mathrm{l}$ of genomic DNA template $(200 \mathrm{ng} / \mu \mathrm{l})$, $35.5 \mu \mathrm{l}$ sterile deionized water, $5 \mu \mathrm{l}$ 10X Ex Taq buffer, forward and reverse primers ( 20 pmol each), $4 \mu \mathrm{l}$ dNTPs (2.5 mM), and Ex Taq DNA polymerase (3 U). PCR amplification conditions were as follows: initial denaturation at $94{ }^{\circ} \mathrm{C}$ for $5 \mathrm{~min} ; 30$ cycles of denaturation at $94^{\circ} \mathrm{C}$ for $30 \mathrm{~s}$, annealing at $58{ }^{\circ} \mathrm{C}$ for $30 \mathrm{~s}$, extension at $72{ }^{\circ} \mathrm{C}$ for $1 \mathrm{~min} 30 \mathrm{~s}$; and a final extension at $72^{\circ} \mathrm{C}$ for $5 \mathrm{~min}$. PCR reactions were carried out using a TaKaRa PCR Thermal Cycler Dice ${ }^{\circledR}$ Gradient (Takara Bio Inc, Japan). The PCR products were purified using an AccuPrep ${ }^{\circledR}$ Gel Purification Kit (Bioneer, Daejeon, Korea Rep), after which they were cloned into a BamH and Sal digested pMal-c2x expression vector (New England Biolabs, UK) using a EzFusion $^{\text {TM }}$ Cloning Kit (Enzynomics, Korea Rep) following the manufacturer's protocol. The recombinant plasmids were transformed into E. coli $\mathrm{DH} 5 \mathrm{a}$ using standard protocols. The clones were purified using an AccuPrep ${ }^{\circledR}$ Nano-Plus Plasmid Mini Extraction Kit (Bioneer, Daejeon, Korea Rep) and then again transformed into E. coli BL21 (DE3) cells for protein expression.

\section{Overexpression and purification of recombinant Gaa16Bcr}

The E. coli cells carrying Gaa16Bc-pMal-c2x were cultured overnight at $37^{\circ} \mathrm{C}$ in $5 \mathrm{~mL}$ of Luria broth (LB) containing $100 \mathrm{mg} / \mathrm{mL}$ of ampicillin. From the overnight culture, $3 \mathrm{~mL}$ was re-inoculated into $250 \mathrm{~mL}$ of fresh media and incubated until mid-logarithmic phase $\left(\mathrm{OD}_{600 \mathrm{~nm}}=0.6-0.7\right)$. To overexpress recombinant proteins, isopropyl- $\beta$-邓-thiogalactopyranoside (IPTG) was added to a final concentration of $0.05 \mathrm{mM}$ and the cultures were incubated at $20^{\circ} \mathrm{C}$ for 20 hours. The cells were harvested by centrifugation at $8000 \times \mathrm{g}$ for $15 \mathrm{~min}$. The collected cells were re-suspended in a column buffer (200 mM NaCl, $20 \mathrm{mM} \mathrm{Tris-HCl})$ and frozen at $-20^{\circ} \mathrm{C}$ overnight.

The frozen cells were thawed on ice and then disrupted by sonication. The supernatants were separated by centrifugation at $11,000 \mathrm{rpm}$ for $20 \mathrm{~min}$ at $4{ }^{\circ} \mathrm{C}$. The recombinant Gaa16Bc (rGaa16Bc) was purified from the soluble fraction using the $\mathrm{pMal}^{\mathrm{TM}}$ Protein Fusion \& Purification System (New England Biolab, UK) according to the manufacturer's instructions and analyzed by SDS-PAGE. Gels were stained with Coomassie brilliant blue to visualize proteins. The concentrations of the purified recombinant proteins were determined using a BCA Protein Assay Reagent Kit (Thermo Fisher Scientific Inc, USA).

\section{Enzyme activity assays}

To determine the biochemical properties of rGaa16Bc, we performed enzyme assays to assess the optimum temperature and $\mathrm{pH}$ for enzyme activity, as well as protein thermostability, and the effects of metal ions and chelators. The enzyme activities were measured using modified DNS methods [29]. The reaction conditions were as follows: $100 \mu \mathrm{L}$ of $1 \%$ agarose (Lonza, Switzerland), $95 \mu \mathrm{L}$ of proper buffer and $5 \mu \mathrm{L}$ of diluted enzyme, incubated for $5 \mathrm{~min}$ at $55^{\circ} \mathrm{C}$. The optimum temperature assay was carried out at 45 to $70^{\circ} \mathrm{C}$ with $5{ }^{\circ} \mathrm{C}$ intervals. To assess the optimum $\mathrm{pH}$, enzyme activity was measured from $\mathrm{pH}$ 4.0 to $\mathrm{pH} 10.0$ with $\mathrm{pH} 1.0$ intervals. To analyze thermostability, rGaa16Bc was pre-incubated at 45 , 50, or $55^{\circ} \mathrm{C}$ for $30,60,90$ and $120 \mathrm{~min}$. and enzyme activity was measured every $30 \mathrm{~min}$ until $120 \mathrm{~min}$. The relative activity was calculated in comparison to the maximum agarolytic activity, which was set at $100 \%$. 
To determine the kinetic parameters of the recombinant protein, the agarolytic activities of rGaa16Bc were measured using various concentration of agarose ranging from 0.25 to $10 \mathrm{mg} / \mathrm{mL}$ under optimal condition. The $K_{\mathrm{m}}, V_{\mathrm{max}}$ and $K_{\text {cat }}$ values were calculated using GraphPad Prism, version 8.3.1 (GraphPad Software, Inc, USA).

\section{Analysis of hydrolytic action and substrate specificity}

TLC was used to analyze the hydrolytic pattern of rGaa16Bc. D-galactose (Sigma-Aldrich, USA), neoagarobiose, agarotriose, neoagarotetraose, and neoagarohexaose (all from Carbosynth, UK) were used as standards. Agarose, neoagarohexaose, neoagarotetraose, and neoagarobiose were hydrolyzed by rGaa16Bc under standard conditions. The hydrolytic products were applied to a silica gel 60 TLC plate (Merck, Germany), which was developed using a solvent system of n-butanol: acetic acid: dH2O (2:1:1 $[\mathrm{v} / \mathrm{v}]$ ). Spots were visualized by spraying orcinol dip reagent (80 $\mathrm{mg}$ of orcine monohydrate was dissolved in $160 \mathrm{~mL}$ of acetone, to which $8 \mathrm{~mL}$ of sulfuric acid was added), followed by heating at $110{ }^{\circ} \mathrm{C}$ in a drying oven for $10 \mathrm{~min}$.

\section{Product detection by HPLC-ELSD-MS}

The agarose degradation products obtained from the treatment with rGaa16Bc were analyzed by HPLCELSD-MS using a C18 reversed phase column, YMC-Pack Pro C18 $(250 \mathrm{~mm} \times 4.6 \mathrm{~mm}, 32 \mu \mathrm{m}$ particle size) from YMC (Kyoto, Japan). The HPLC-ELSD-MS system comprised an Agilent 1260 Infinity module coupled to both an evaporative light scattering detector 1260 Infinity and a single quadrupole mass spectrometer 6120B (Agilent, Santa Clara, CA, USA) equipped with an electrospray ionization source. For the mobile phase, a linear solvent gradient of $100 \%$ water / $0 \%$ acetonitrile to $100 \%$ acetonitrile was used for $5 \mathrm{~min}$ followed by the use of $100 \%$ acetonitrile for an additional $5 \mathrm{~min}$. The flow rate of the mobile phase was a constant $0.5 \mathrm{~mL} / \mathrm{min}$, and the injection volume was $20 \mu \mathrm{L}$. The signals corresponding to neoagarobiose and neoagarotetraose in the HPLC-ELSD chromatogram were identified by comparing the retention time and pseudomolecular ions with those of the analytical standards. The presence of neoagarotriose in the chromatogram was confirmed by the molecular formula obtained using highresolution ESI mass spectrometry using a SYNAPT-G2 system.

\section{Declarations}

\section{Ethics approval and consent to participate}

Not applicable

\section{Consent for publication}

Not applicable

\section{Availability of data and materials}


All data generated or analyzed during this study are included in this published article.

\section{Competing interests}

The authors declare that they have no competing interests.

\section{Funding}

This work was supported by the grant from Korea Institute of Ocean Science \& Technology (KIOST) (Research grant-PE99822).

\section{Authors' contributions}

YL, EJ, YJL and HC performed the majority of the laboratory works. TYE and YG contributed to the interpretation of the results. YHK, SDM and SAH also performed the laboratory experiments. DHK helped to revise the manuscript. YL wrote the manuscript and overall work was supervised by $\mathrm{CO}$. All authors read and approved the final manuscript.

\section{Acknowledgements}

Not applicable

\section{References}

1. Fu XT, Kim SM. Agarase: review of major sources, categories, purification method, enzyme characteristics and applications. Mar Drugs. 2010;8:200-18.

2. Kobayashi R, Takisada M, Suzuki T, Kirimura K, Usami S. Neoagarobiose as a novel moisturizer with whitening effect. Biosci Biotechnol Biochem. 1997;61:162-3.

3. Zhang YH, Song XN, Lin Y, Xiao Q, Du XP, Chen YH, Xiao AF. Antioxidant capacity and prebiotic effects of Gracilaria neoagaro oligosaccharides prepared by agarase hydrolysis. Int J Biol Macromol. 2019;137:177-86.

4. Wu Y-R, Zhou Z-R, Zhao M, Lin B, Zhong M, Hu Z. Molecular characterization of the thermostability and carbohydrate-binding module from a newly identified GH118 family agarase, AgaXa. Process Biochem. 2017;52:192-9.

5. Hu Z, Lin BK, Xu Y, Zhong MQ, Liu GM. Production and purification of agarase from a marine agarolytic bacterium Agarivorans sp. HZ105. J Appl Microbiol. 2009;106:181-90.

6. Leon O, Quintana L, Peruzzo G, Slebe JC. Purification and Properties of an Extracellular Agarase from Alteromonas sp. Strain C-1. Appl Environ Microbiol. 1992;58:4060-3.

7. Kim BJ, Kim HJ, Duck Ha S, Hee Hwang S, Seok Byun D, Ho Lee T, Yul Kong J. Purification and characterization of $\beta$-agarase from marine bacterium Bacillus cereus ASK202. Biotech Lett. 1999;21:1011-5. 
8. Cui F, Dong S, Shi X, Zhao X, Zhang X-H. Overexpression and characterization of a novel thermostable $\beta$-agarase YM01-3, from marine bacterium Catenovulum agarivorans YM01(T). Marine drugs. 2014;12:2731-47.

9. Oh C, Nikapitiya C, Lee Y, Whang I, Kim SJ, Kang DH, Lee J. Cloning, purification and biochemical characterization of beta agarase from the marine bacterium Pseudoalteromonas sp. AG4. J Ind Microbiol Biotechnol. 2010;37:483-94.

10. Morrice LM, McLean MW, Williamson FB, Long WF. beta-agarases I and II from Pseudomonas atlantica. Purifications and some properties. Eur J Biochem. 1983;135:553-8.

11. Sugano $Y$, Terada I, Arita M, Noma M, Matsumoto T. Purification and characterization of a new agarase from a marine bacterium, Vibrio sp. strain JT0107. Appl Environ Microbiol. 1993;59:154954.

12. Temuujin U, Chi W-J, Chang Y-K, Hong S-K. Identification and Biochemical Characterization of Sco3487 from Streptomyces coelicolor A3(2), an Exo- and Endo-Type $\beta$-Agarase-Producing Neoagarobiose. J Bacteriol. 2012;194:142-9.

13. Kim HT, Lee S, Lee D, Kim HS, Bang WG, Kim KH, Choi IG. Overexpression and molecular characterization of Aga50D from Saccharophagus degradans 2-40: an exo-type beta-agarase producing neoagarobiose. Appl Microbiol Biotechnol. 2010;86:227-34.

14. Lee Y, Jo E, Lee YJ, Hettiarachchi SA, Park GH, Lee SJ, Heo SJ, Kang DH, Oh C. A Novel Glycosyl Hydrolase Family 16 beta-Agarase from the Agar-Utilizing Marine Bacterium Gilvimarinus agarilyticus JEA5: the First Molecular and Biochemical Characterization of Agarase in Genus Gilvimarinus. J Microbiol Biotechnol. 2018;28:776-83.

15. POTIN P, RICHARD C, ROCHAS C. KLOAREG B: Purification and characterization of the a-agarase from Alteromonas agarlyticus (Cataldi) comb. nov., strain GJ1B. Eur J Biochem. 1993;214:599-607.

16. Liu J, Liu Z, Jiang C, Mao X. Biochemical Characterization and Substrate Degradation Mode of a Novel alpha-Agarase from Catenovulum agarivorans. J Agric Food Chem. 2019;67:10373-9.

17. Lee $\mathrm{CH}$, Lee $\mathrm{CR}$, Hong SK. Biochemical characterization of a novel cold-adapted agarotetraoseproducing alpha-agarase, AgaWS5, from Catenovulum sediminis WS1-A. Appl Microbiol Biotechnol. 2019;103:8403-11.

18. Lee Y, Lee SJ, Park GH, Heo SJ, Umasuthan N, Kang DH, Oh C. Draft genome of agar-degrading marine bacterium Gilvimarinus agarilyticus JEA5. Mar Genomics. 2015;21:13-4.

19. Lee Y, Jo E, Lee YJ, Hettiarachchi SA, Park GH, Lee SJ, Heo SJ, Kang DH, Oh C. A novel glycosyl hydrolase family 16 beta-agarase from the agar-utilizing marine bacterium Gilvimarinus agarilyticus JEA5: the first agarase molecular and biochemical characterization in the genus Gilvimarinus. J Microbiol Biotechnol. 2018;28:776-83.

20. Henshaw J, Horne-Bitschy A, van Bueren AL, Money VA, Bolam DN, Czjzek M, Ekborg NA, Weiner RM, Hutcheson SW, Davies GJ, et al. Family 6 carbohydrate binding modules in beta-agarases display exquisite selectivity for the non-reducing termini of agarose chains. J Biol Chem. 2006;281:17099107. 
21. Alkotaini B, Han NS, Kim BS. Enhanced catalytic efficiency of endo-beta-agarase I by fusion of carbohydrate-binding modules for agar prehydrolysis. Enzyme Microb Technol. 2016;93-94:142-9.

22. Wang Y, Liu T, Guo S, Zhang P, Sun P, Chen M, Ming H. Characterization and overexpression of a glycosyl hydrolase family 16 beta-agarase Aga0917 from Pseudoalteromonas fuliginea YTW1-15-1. J Gen Appl Microbiol. 2019;64:276-83.

23. Hsu PH, Wei CH, Lu WJ, Shen F, Pan CL, Lin HT. Extracellular production of a novel endo-betaagarase AgaA from Pseudomonas vesicularis MA103 that cleaves agarose into neoagarotetraose and neoagarohexaose. Int J Mol Sci. 2015;16:5590-603.

24. Zhang WB, Xu JN, Liu D, Liu H, Lu XZ, Yu WG. Characterization of an alpha-agarase from Thalassomonas sp LD5 and its hydrolysate. Appl Microbiol Biotechnol. 2018;102:2203-12.

25. Petersen TN, Brunak S, von Heijne G, Nielsen H. SignalP 4.0: discriminating signal peptides from transmembrane regions. Nat Methods. 2011;8:785.

26. Letunic I, Doerks T, Bork P. SMART: recent updates, new developments and status in 2015. Nucleic Acids Res. 2015;43:D257-60.

27. Sigrist CJ, de Castro E, Cerutti L, Cuche BA, Hulo N, Bridge A, Bougueleret L, Xenarios I. New and continuing developments at PROSITE. Nucleic Acids Res. 2013;41:D344-7.

28. Madeira F, Park YM, Lee J, Buso N, Gur T, Madhusoodanan N, Basutkar P, Tivey ARN, Potter SC, Finn RD, Lopez R. The EMBL-EBI search and sequence analysis tools APIs in 2019. Nucleic acids research. 2019;47:W636-41.

29. Oh C, Nikapitiya C, Lee Y, Whang I, Kang DH, Heo SJ, Choi YU, Lee J. Molecular cloning, characterization and enzymatic properties of a novel betaeta-agarase from a marine isolate Psudoalteromonas SP. AG52. Braz J Microbiol. 2010;41:876-89.

30. Declarations.

\section{Figures}




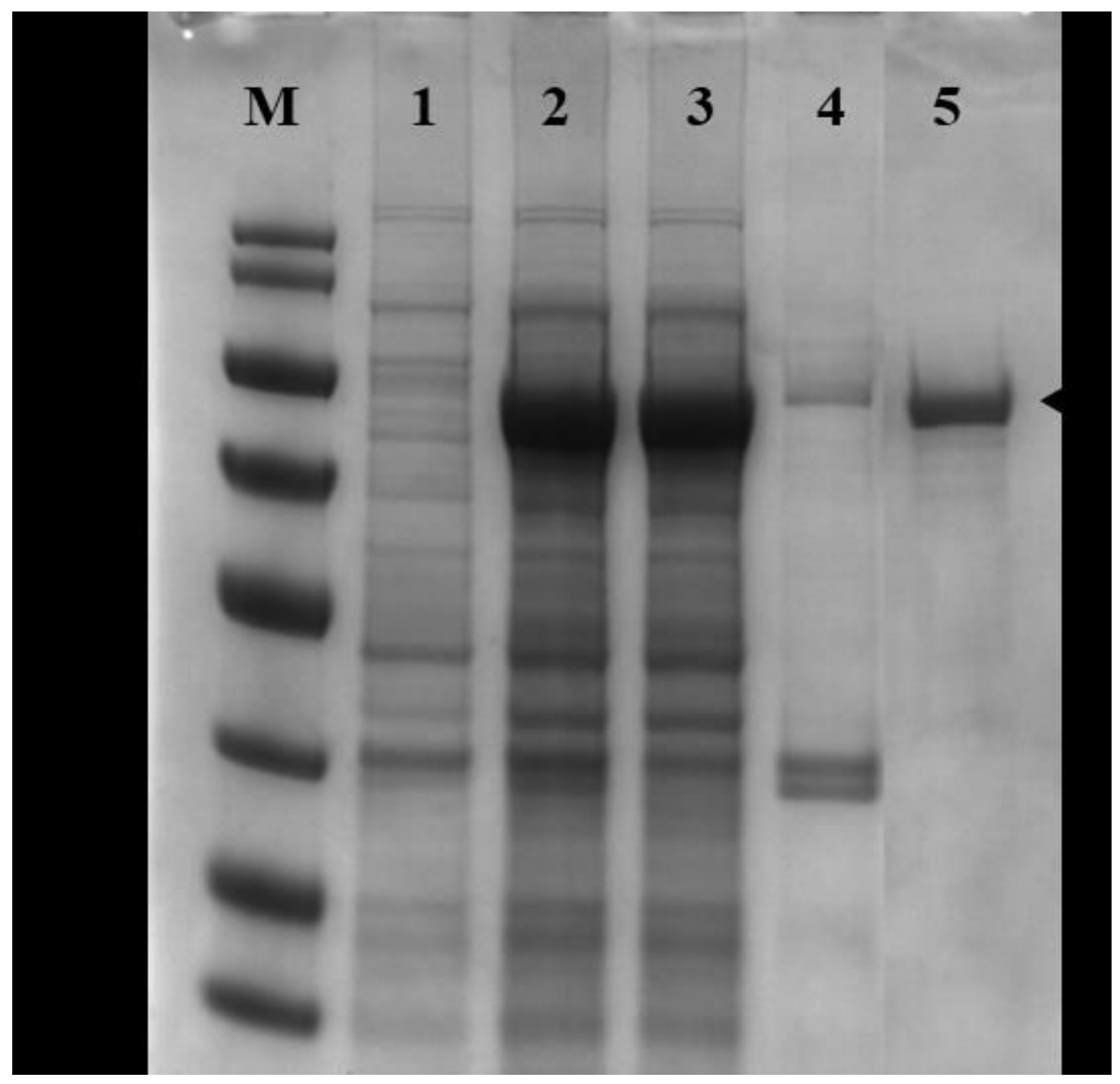

\section{Figure 1}

SDS-PAGE of the rGaa16Bc protein. Samples of rGaa16Bc were separated on a $12 \%$ SDS-PAGE gel and stained with Coomassie brilliant blue. M: Molecular mass marker (Thermo scientific, USA). Lane 1: whole cell lysates from E. coli BL21 (DE3) before induction; lane 2: whole cell lysates after IPTG induction; lane 3: total soluble cellular extract after induction; lane 4: total insoluble cellular extract after induction; lane 5: purified rGaa16Bc. 

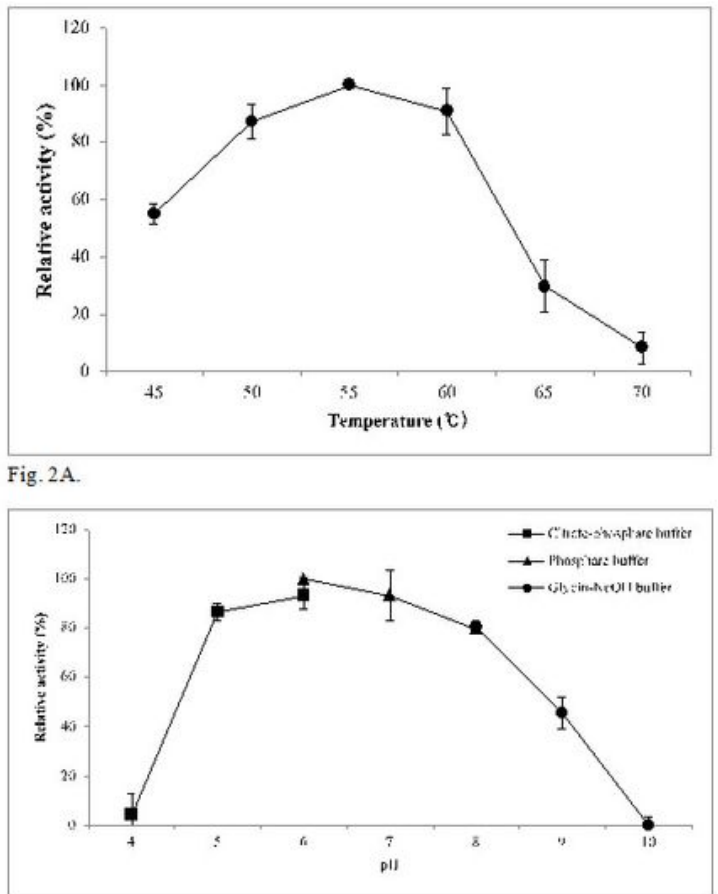

Fig. 2B.
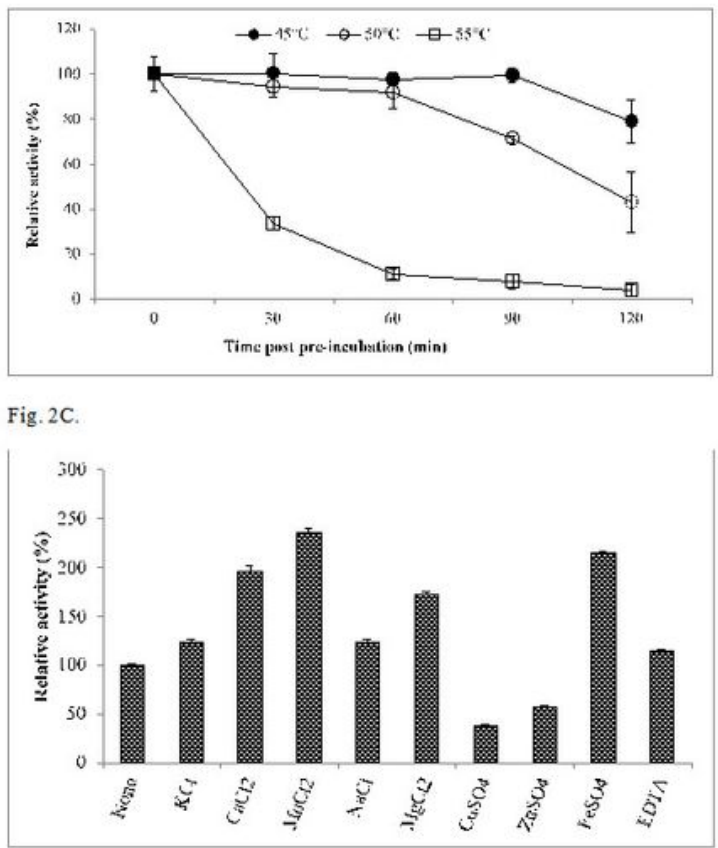

Fig. 2D.

\section{Figure 2}

Characterization of biochemical properties of purified rGaa16Bc. The effect of temperature (A), pH (B), thermostability (C) and metal ions and chelators (D) on the rGaa16Bc activity. 
(A)

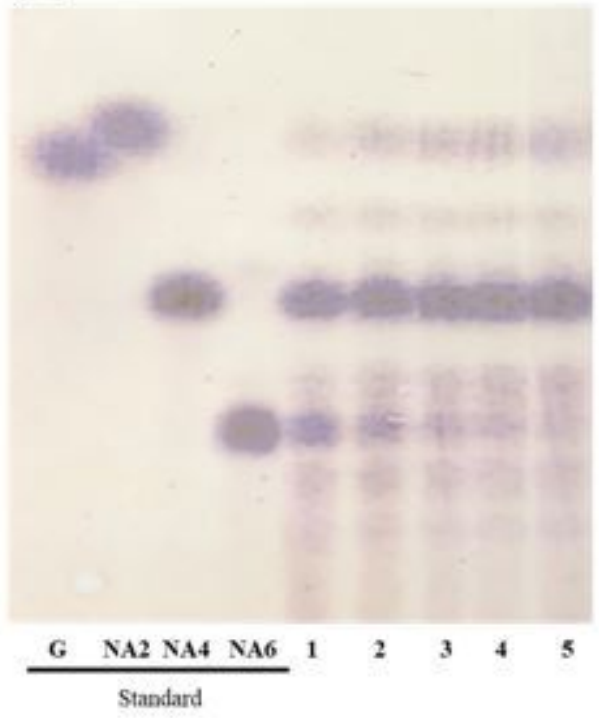

(B)

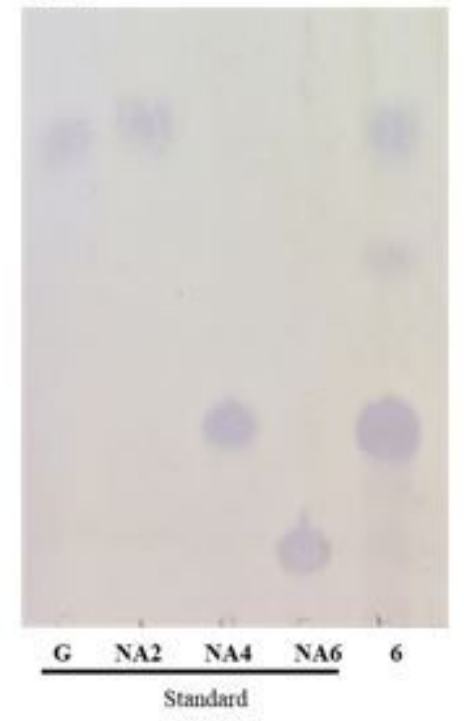

(C)

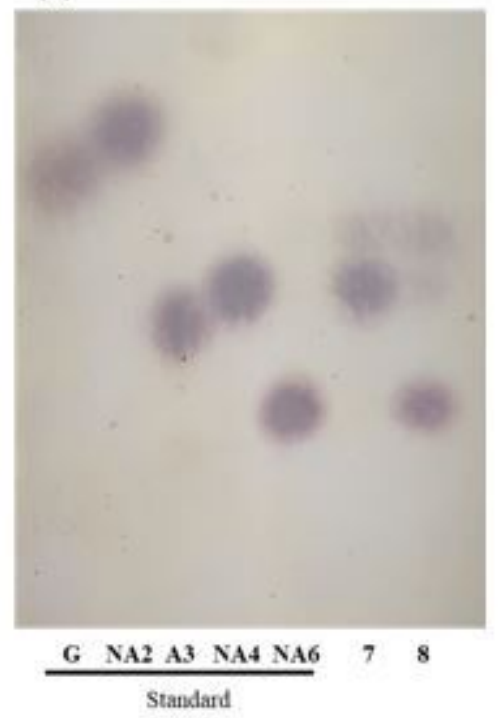

Figure 3

Thin layer chromatography of hydrolysis products of rGaa16Bc on agarose, neoagarotetraose (NA4), and neoagarohexaose (NA6). D-galactose (G), neoagarobiose (NA2), NA4, NA6 and agarotirose (A3) are used as standard. The assays were conducted under standard conditions. Lane 1-5, agarose hydrolyzed by rGaa16Bc for 10, 30, 60, 120 and 180 min; lane 6, agarose hydrolyzed by rGaa16Bc overnight; lane 7-8, neoagarotetraose and neoagarohexaose hydrolyzed by rGaa16Bc for 1 hour. 


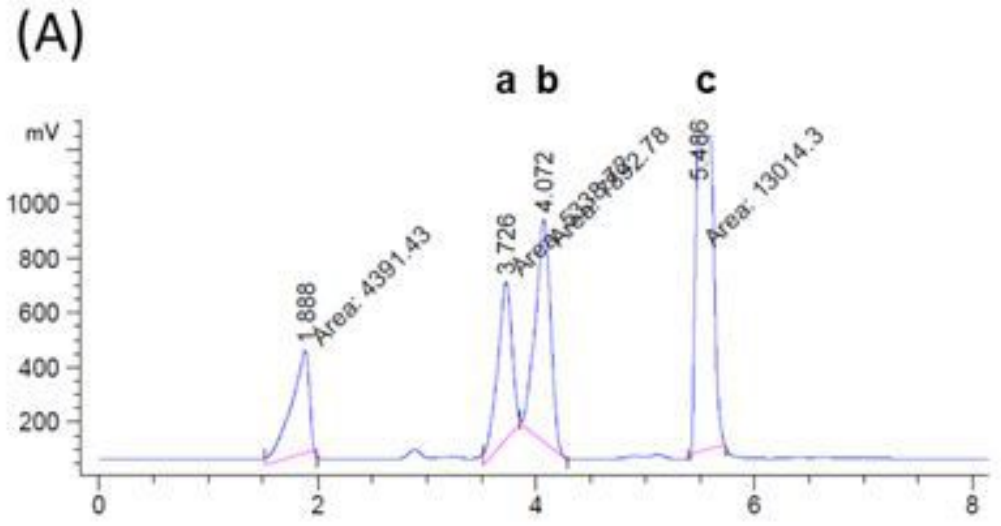

(B)

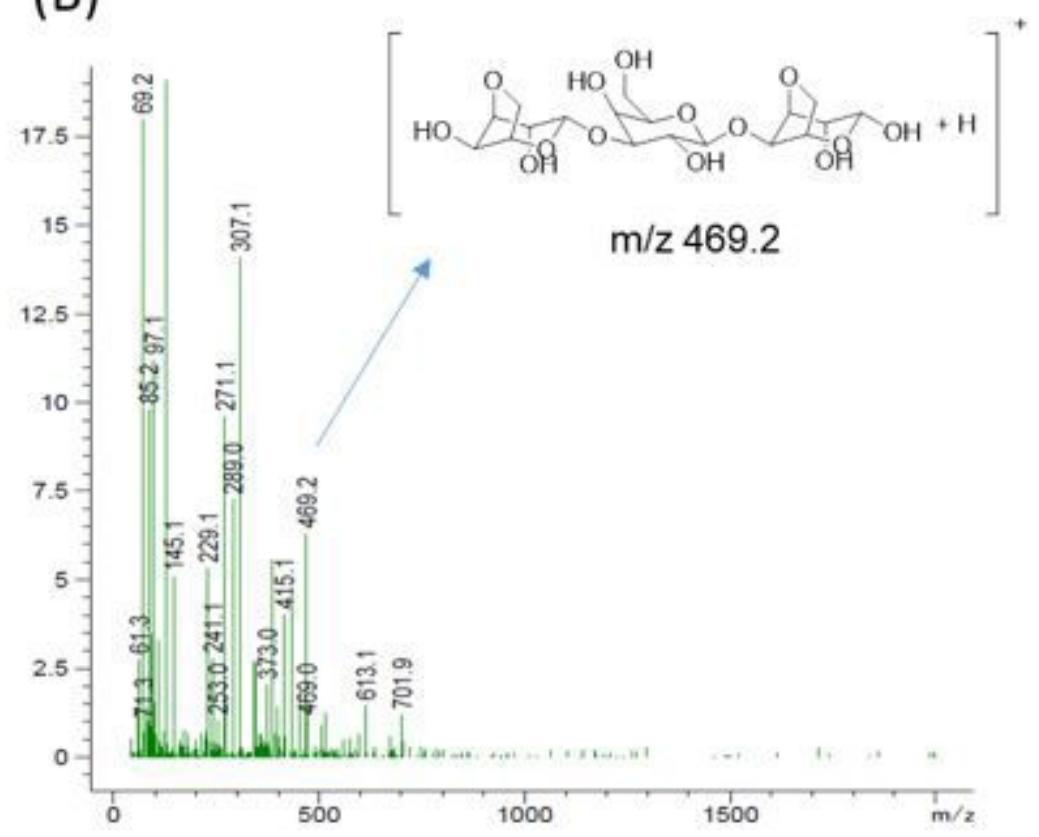

Figure 4

Identification of agarose degradation products. HPLC-ELSD chromatogram of the agarose degradation products (A) and positive-ion ESI-MS spectrum of $b(B)$. a, neoagarobiose $([\mathrm{M}+\mathrm{Na}]+347.0) ; b$, neoagarotriose $([\mathrm{M}+\mathrm{H}]+469.2) ; \mathrm{c}$, neoagarotetraose $([\mathrm{M}-\mathrm{H}]-629.1)$. 